\title{
Successful thrombolysis with recombinant tissue plasminogen activator after antagonizing dabigatran by idarucizumab: a case report
}

\author{
Annemarie Gawehn $n^{1,2}$, Yassine Ayari ${ }^{1,2}$, Christian Heuschkel ${ }^{1,2}$, Matthias Kaste ${ }^{1,2}$ and Pawel Kermer ${ }^{1,2^{*}}$
}

\begin{abstract}
Background: Effective anticoagulation routinely precludes patients from receiving intravenous thrombolysis with recombinant tissue plasminogen activator to reverse severe symptoms of ischemic stroke. We report what we believe to be the first case of ischemic stroke successfully treated with recombinant tissue plasminogen activator after antagonizing dabigatran with the monoclonal antibody idarucizumab, recently approved worldwide.

Case presentation: A 75-year-old Caucasian man presented to our hospital with severe aphasia and mild hemiparesis. After providing written consent, he received two doses of $2.5 \mathrm{~g}$ of idarucizumab over 20 minutes followed by standard protocol in-label recombinant tissue plasminogen activator application. All symptoms resolved within $1 \mathrm{~h}$.

Conclusions: Applying a recombinant tissue plasminogen activator after antagonizing dabigatran with idarucizumab is feasible and easy to manage in an emergency room or stroke unit. Thus, idarucizumab represents a new therapeutic option for patients receiving dabigatran treatment, reestablishing their eligibility for recombinant tissue plasminogen activator thrombolysis.
\end{abstract}

Keywords: Ischemic stroke, Thrombolysis, Dabigatran, Idarucizumab, recombinant tissue plasminogen activator

\section{Background}

Neurologists have used dabigatran mostly for secondary prevention of cardioembolic stroke in patients with atrial fibrillation since the phase III RE-LY trial [1] showed positive results for the prevention of stroke or systemic embolism as compared with warfarin. Besides dabigatran, three additional non-vitamin-K-dependent oral anticoagulants (NOACs) [24] are currently available. Substantially decreased rates of bleeding complications in comparison with warfarin, especially when considering intracerebral hemorrhage, are an advantage of NOAC therapy. However, one major concern was the lack of specific antidotes. With the approval of idarucizumab, a novel monoclonal antibody fragment with a high potency to reverse the anticoagulant effects of dabigatran within minutes $[5,6]$, the question arose if recombinant tissue plasminogen activator (rt-PA) could be used after

\footnotetext{
* Correspondence: pkermer@gwdg.de

${ }^{1}$ Department of Neurology, Nordwest-Krankenhaus Sanderbusch GmbH, Am Gut Sanderbusch 1, 26452 Sande, Germany

${ }^{2}$ Academic Clinical Department, University Medical Center Gottingen, Gottingen, Germany
}

reversal of dabigatran with idarucizumab in individuals with newly occurring ischemic stroke. Since the introduction of NOAC therapy, these patients have frequently been excluded from thrombolytic therapy, owing to the unpredictable risk of bleeding.

\section{Case presentation}

A 75-year-old, right-handed Caucasian man with a history of embolic stroke and atrial fibrillation was admitted on 30 January 2016 to the stroke unit of our primary care hospital for severe aphasia and right-sided hemiparesis with sudden onset of symptoms about $1 \mathrm{~h}$ before presentation. He was receiving NOAC therapy with dabigatran $110 \mathrm{mg}$ twice daily. His $\mathrm{CHA}_{2} \mathrm{DS}_{2}$-VASc score was 6 points (on scale representing congestive heart failure [or left ventricular systolic dysfunction] 1 point, hypertension [blood pressure consistently above $140 / 90 \mathrm{mmHg}$ or treated hypertension on medication] 1 point, age $\geq 75$ years 2 points, diabetes mellitus 1 point, prior stroke or transient ischemic attack or thromboembolism 2 points, vascular disease [e.g., peripheral 
artery disease, myocardial infarction, aortic plaque] 1 point, age 65-74 years 1 point, sex category [female sex] 1 point), and his HAS-BLED score was 3 points (with scale representing hypertension, abnormal renal and liver function, stroke, bleeding, labile international normalized ratio, elderly, drugs or alcohol). Correct dabigatran therapy of $110 \mathrm{mg}$ twice daily could be verified by the accompanying spouse with last intake on the same morning approximately $9.5 \mathrm{~h}$ before. Besides cardioembolic stroke, the patient's medical history consisted of structural epilepsy based on middle cerebral artery ischemia in March 2015 treated with levetiracetam $500 \mathrm{mg}$ twice daily and arterial hypertension treated with amlodipine, metoprolol, and torasemide.

The patient's impairment of production and comprehension of speech was severe. It was possible for him to communicate, but only to a very limited extent. His hemiparesis was rather mild. His initial National Institutes of Health Stroke Scale (NIHSS) score was 5. No convulsions or lack of consciousness was reported or noticed. According to the patient's spouse, his symptoms were not comparable to prior seizure symptomatology displayed by sudden loss of consciousness and generalized tonic-clonic convulsions. As a residual of his prior stroke, the patient had a slight outer rotation of his right foot without gait impairment.

Laboratory examinations done upon admission revealed a slight coagulation disorder (international normalized ratio 1.01, activated partial thromboplastin time [aPTT] 39.0 seconds [upper limit of normal 42 seconds], thrombin time 66.8 seconds [upper limit of normal 22 seconds]). Besides a defect zone arising from ischemic stroke in May 2015, computed tomographic (CT) scans (Fig. 1) displayed no early signs of acute stroke. Taking into account the patient's NIHSS score of 5, no CT angiography or perfusion protocol was performed, in accordance with effective stroke guidelines. Except for the existing oral dabigatran anticoagulation therapy, the patient's history did not reveal any contraindications against systemic thrombolytic therapy. After the patient provided written consent, we applied two doses of 2.5 g idarucizumab according to the current product characteristics and prescribing information within 20 minutes to antagonize dabigatran. Another blood sample showing normalized coagulation parameters preceded immediate weight-adapted intravenous rt-PA therapy. Within $1 \mathrm{~h}$, all symptoms resolved to baseline levels.

A clinical examination done the next day revealed fluent speech with hardly noticeable word-finding difficulties in an aphasia assessment. Detailed conversation was possible again, and the patient reported subjective well-being. Because the patient's symptoms resolved within $1 \mathrm{~h}$ and because of the lack of therapeutic consequences, we abstained from follow-up magnetic resonance imaging scans as part of the stroke workup. The patient's electroencephalogram was free of any epileptic discharges. Echocardiography revealed no evidence of intracardial thrombotic material, and an ultrasound of the brain-supplying arteries did not reveal relevant stenoses. With the patient's low-density lipoprotein cholesterol values being elevated $(160 \mathrm{mg} / \mathrm{dl})$, we initiated therapy with simvastatin $20 \mathrm{mg}$. Dabigatran therapy was reestablished after $24 \mathrm{~h}$. However, on the basis of the patient's age and normal renal function, we chose an increased dose of $150 \mathrm{mg}$ twice daily according to the effective prescribing information. During idarucizumab application and throughout the entire hospital stay, no thrombotic or bleeding complications occurred. The patient's laboratory examination results remained normal, and he was released to home in good health.

\section{Discussion}

Intravenous rt-PA thrombolysis in acute ischemic stroke is considered an emergency intervention allowing an in-label
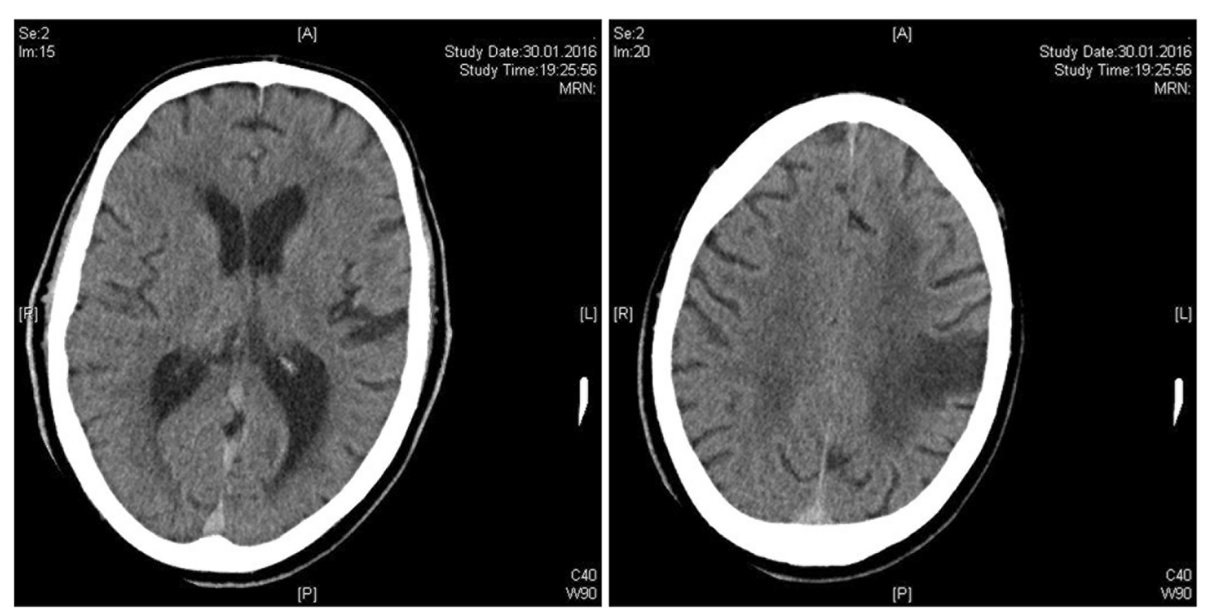

Fig. 1 Computed tomographic scan taken upon admission shows no early signs of acute stroke, but displays the residuals of a cardioembolic stroke in the left hemisphere that had occurred in May 2015 
application of idarucizumab. Interestingly, in our patient, thrombin time was the only clearly pathologic coagulation parameter $9.5 \mathrm{~h}$ after the last medication intake. aPTT was somehow prolonged but still within normal range. A second laboratory examination done immediately after idarucizumab application showed normal coagulation parameters. This allowed in-label use of rt-PA, which is prohibited when anticoagulation therapy is in effect. However, we did not wait for the results, but rather infused rt-PA in order not to lose time to reperfusion of ischemic brain regions. In cases where the second laboratory examinations still show prolonged thrombin time, we suggest immediate termination of rt-PA infusion. However, according to the available idarucizumab data, dabigatran anticoagulation should be abrogated in more than $98 \%$ of patients [6]. Besides our patient, two similar cases $[7,8]$ have recently been reported. In both cases, rt-PA could be administered successfully after reversing anticoagulation effects of dabigatran by using the specific antidote idarucizumab. As for our patient, no adverse events such as thromboembolism or bleeding occurred in these two cases. Still, large registries on the use of idarucizumab should be established with special emphasis on unfavorable outcomes such as thrombotic events, bleeding, and mortality to further explore potential concerns regarding safety and efficacy.

\section{Conclusions}

To our knowledge, and according to available supplier information, we report the first case worldwide of ischemic stroke successfully treated with rt-PA after antagonizing dabigatran with idarucizumab. In line with two other recent German cases, in which the procedure appeared to be feasible, easy to manage, and without severe adverse events, this novel therapeutic option should be considered in individuals presenting with ischemic stroke who are receiving dabigatran therapy. However, further evidence concerning safety and efficacy is needed before this therapeutic regimen can be generally recommended.

\section{Acknowledgements}

Not applicable.

\section{Funding}

No funding available.

\section{Availability of data and material}

All data generated or analyzed during this study are included in this published article and its supplementary information files.

\section{Authors' contributions}

AG was responsible for data acquisition and manuscript preparation. YA was responsible for data acquisition. $\mathrm{CH}$ was responsible for data acquisition and critical revision of the manuscript. MK was responsible for data acquisition and critical revision of the manuscript. PK was responsible for data acquisition and manuscript preparation. All authors read and approved the final manuscript.

\section{Competing interests}

MK reports receiving speaker's honoraria from Boehringer Ingelheim. PK reports receiving speaker's honoraria and compensation for service on advisory boards from Boehringer Ingelheim. The other authors declare that they have no competing interests.

\section{Consent for publication}

Written informed consent was obtained from the patient for publication of this case report and any accompanying images. A copy of the written consent is available for review by the Editor-in-Chief of this journal.

\section{Ethics approval and consent to participate}

Not applicable.

Received: 26 March 2016 Accepted: 30 August 2016

Published online: 29 September 2016

\section{References}

1. Connolly SJ, Ezekowitz MD, Yusuf S, Eikelboom J, Oldgren J, Parekh A, et al. Dabigatran versus warfarin in patients with atrial fibrillation. N Engl J Med. 2009;361:1139-51.

2. Patel MR, Mahaffey KW, Garg J, Pan G, Singer DE, Hacke W, et al. Rivaroxaban versus warfarin in nonvalvular atrial fibrillation. N Engl J Med. 2011;365:883-91.

3. Granger CB, Alexander JH, McMurray JJ, Lopes RD, Hylek EM, Hanna M, et al. Apixaban versus warfarin in patients with atrial fibrillation. N Engl J Med. 2011;365:981-92.

4. Giugliano RP, Ruff CT, Braunwald E, Murphy SA, Wiviott SD, Halperin JL, et al. Edoxaban versus warfarin in patients with atrial fibrillation. N Engl J Med. 2013:369:2093-104.

5. Glund S, Stangier J, Schmohl M, Gansser D, Norris S, van Ryn J, et al. Safety, tolerability, and efficacy of idarucizumab for the reversal of the anticoagulant effect of dabigatran in healthy male volunteers: a randomised, placebo-controlled, double-blind phase 1 trial. Lancet. 2015;386:680-90.

6. Pollack Jr CV, Reilly PA, Eikelboom J, Glund S, Verhamme P, Bernstein RA, et al. Idarucizumab for dabigatran reversal. N Engl J Med. 2015:373:511-20.

7. Schäfer N, Müller A, Wüllner U. Systemic thrombolysis for ischemic stroke after antagonizing dabigatran with idarucizumab-a case report. J Stroke Cerebrovasc Dis. 2016;25:e126-7.

8. Berrouschot J, Stoll A, Hogh T, Eschenfelder CC. Intravenous thrombolysis with recombinant tissue-type plasminogen activator in a stroke patient receiving dabigatran anticoagulant after antagonization with idarucizumab. Stroke. 2016:47:1936-8.

Submit your next manuscript to BioMed Central and we will help you at every step:

- We accept pre-submission inquiries

- Our selector tool helps you to find the most relevant journal

- We provide round the clock customer support

- Convenient online submission

- Thorough peer review

- Inclusion in PubMed and all major indexing services

- Maximum visibility for your research 